\title{
Efeito do diluidor "baken" modificado na longevidade espermática de cão
}

\section{Effect of modificated extender "baken" on longevity of canine sperm}

\author{
Karen Mascaro Gonçalves da Silva, ${ }^{1 *}$ Frederico Ozanam Papa, ${ }^{* *}$ Maria Madalena Pessoa Guerra, ${ }^{*}$ \\ Cristiane Scavuzzi Moura, ${ }^{*}$ Áurea Wischral*
}

\begin{abstract}
Resumo
Têm-se relatado diversos trabalhos relacionados com a biotecnologia do sêmen de cão, comprovando o interesse no aperfeiçoamento das raças, além de diminuição de custos, uma vez que a tecnologia do sêmen permite reduzir o número de machos em um canil. O diluidor "baken" é utilizado no resfriamento do sêmen de eqüino e de asinino. No entanto, ainda não se tem relato de seu uso na preservação do sêmen da espécie canina. Desta forma, este trabalho teve como objetivo avaliar a eficácia do diluidor "baken" modificado no resfriamento do sêmen de cão. Para isso, foram coletados sêmen de quatro cães, sem raça definida, e avaliados os parâmetros de motilidade e integridade de membrana. Observou-se que a membrana espermática, assim como a motilidade individual progressiva, mantiveram-se preservadas até 48 horas de resfriamento. 0 meio "baken" modificado constitui diluidor eficaz no procedimento de refrigeração de sêmen de cão.
\end{abstract}

Palavras-chave: sêmen, cão, resfriamento, "baken", diluidores.

\begin{abstract}
There are several jobs with biotechnology of the canine semen, proving the interest in improvement of the races, besides cost decrease, once that, the technology of the semen allows to reduce the number of males in a kennel. The extending "baken" is used in the cooling of the equine and asinus semen. However, still we do not have report of its use in the semen preservation of canine. Thus, this work had as goal evaluates effectiveness of the extending "baken" modified in the cooling of the canine semen. Semen from four canines was evaluated from motility and membrane integrity and they were conserved from 48 hours at cooled. The baken extender was effective to cool canine's semen.
\end{abstract}

Keywords: semen, canine, cooling, "baken", extenders.

\section{Introdução}

Nos últimos anos tem-se observado crescente interesse em técnicas que possibilitem maior aproveitamento do material genético oriundo de reprodutores caninos (Silva et al., 2001). Sabe-se, portanto, que na industrialização do sêmen, o diluidor é um fator de grande importância para a manutenção da viabilidade dos espermatozóides (Moura, 2000), pois, o sêmen diluído pode ser refrigerado por alguns dias, e quando reaquecido, utilizado para a inseminação artificial (Cunha et al., 1997), desde que apresente, pelo menos, 50 a $70 \%$ de motilidade, segundo Andersen (1974) e Seager et al. (1975), assim como percentual de patologias espermáticas inferior a 20\% (Manual para Exame Andrológico e Avaliação Seminal - CBRA). Indiscutivelmente, a principal vantagem é a possibilidade de inseminar cadelas de diferentes localizações geográficas (Pinto et al., 1999).

Diluidores à base de gema de ovo e leite desnatado são os mais utilizados para sêmen de cão, e diversas substâncias podem ser empregadas, entre elas, solução de citrato-gema, IVT, TRIS, citrato-bicarbonato-gema de ovo, Kenney (Gill et al., 1970; Seager e Fletcher, 1972; Fastad, 1984; Province et al., 1984; Schafer et al., 1987; Morton et al., 1989; Bouchard et al., 1990; Linde-Forsberg, 1993; England et al., 1996). Todavia, para a refrigeração do sêmen de cão, têm sido utilizados diluidores à base de gema de ovo e leite, com o objetivo de proteger os espermatozóides do choque térmico, fornecer nutrientes e manter o pH (Province at al., 1984).

Segundo Moura (2000), a ação crioprotetora do diluente à base de leite desnatado é inferior àquela exercida pela gema de ovo de galinha ou codorna, no procedimento de refrigeração do sêmen de cão a $5^{\circ} \mathrm{C}$. Province et al. (1984) obtiveram 50\% de motilidade espermática no sêmen refrigerado de cão utilizando diluidores com $20 \%$ de gema de ovo, com ou sem adição do glicerol, durante dois a quatro dias. Da mesma forma, Cunha et al. (1997) observaram que diluidores à base de leite desnatado e glicina-gema apresentaram $60 \%$ de motilidade e $2 \%$ de vigor, após 72 horas de resfriamento a

\footnotetext{
1 Rua dos Navegantes, 1907apto. 701, Boa Viagem, Recife, PE - CEP:51021-000. e-mail: karenmascaro1@hotmail.com/ tel.: (81)3467-9886.

* Universidade Federal Rural de Pernambuco/ UFRPE.

** Universidade Estadual Paulista/UNESP, Faculdade de Medicina Veterinária e Zootecnia de Botucatu/FMVZ.
} 
$5^{\circ} \mathrm{C}$, demonstrando proteção efetiva dos meios diluidores sobre a integridade das membranas espermáticas e, conseqüentemente, viabilizando o processo de refrigeração.

O meio "baken" foi proposto por Nishikawa (1959), ao diluir o sêmen de jumento e armazená-lo a $4^{\circ} \mathrm{C}$, conseguindo a sua longevidade durante 337 horas. Mello et al. (2000) também avaliaram a longevidade do sêmen de jumentos utilizando o diluidor "baken" modificado e Kenney, comparando-se a fração rica e o ejaculado total, onde observaram aumento da motilidade total, motilidade progressiva e vigor espermático do sêmen preservado com o diluidor "baken" quando comparado ao sêmen preservado com o diluidor "Kenney", em ambas as frações. Silva (2001), resfriando sêmen de eqüinos a $5^{\circ} \mathrm{C}$, conseguiu longevidade espermática até 72 horas. Todavia, essa autora constatou que a fertilidade só foi atingida com o sêmen preservado durante 24 horas.

Diante do exposto, este trabalho teve como objetivo, avaliar a eficácia do meio diluidor "baken" modificado (Silva, 2001) na refrigeração de sêmen de cão.

\section{Material e métodos}

Foram utilizados três ejaculados de quatro cães, sem raça definida. Os animais foram mantidos no canil da FMVZ-UNESP e alimentados com ração, além de água ad libitum. Inicialmente, foram realizados exames andrológicos, vacinação e vermifugação dos animais. O método de colheita utilizado foi a manipulação digital do pênis, em tubos coletores de vidro graduados, pré-aquecidos à temperatura de $37^{\circ} \mathrm{C}$, a intervalo de 48 horas. Cada ejaculado foi avaliado imediatamente após a colheita (M0) e após 24 (M1), 48 (M2), 72 (M3), 96 (M4) e 120 (M5) horas após o resfriamento, segundo as características macroscópicas (cor, volume e odor) e microscópicas (motilidade e concentração). A motilidade foi avaliada onde uma gota de sêmen foi colocada sobre lâmina aquecida $\left(38^{\circ} \mathrm{C}\right)$ recobrindo-a com lamínula; o exame foi realizado através de microscopia de contraste de fase $(200 x)$ e o resultado obtido, expresso em porcentagem (0-100). Adicionalmente, obteve-se a concentração espermática pelo método da contagem em câmara de Neubauer para, em seguida, calcular o número de espermatozóides viáveis/ejaculado. As amostras foram, também, submetidas à análise de fluorescência para verificação da integridade da membrana plasmática, de acordo com a técnica descrita por Harrison et al. (1990).

A seguir, as amostras foram diluídas em meio "baken" modificado (Silva, 2001) e centrifugadas a 400xg, durante 10 minutos. O sobrenadante foi desprezado e o "pellet" foi ressuspenso no mesmo meio, determinando a concentração final de $50 \times 10^{6}$ espermatozóides $/ \mathrm{ml}$. Em seguida, cinco alíquotas de cada amostra foram armazenadas em tubos plásticos de $1,5 \mathrm{ml}$ e refrigeradas em freezer até atingirem a temperatura de $4^{\circ} \mathrm{C}$, quando, em seguida, foram armazenadas em geladeira previamente estabilizada a $4^{\circ} \mathrm{C}$. Para a avaliação das amostras, o sêmen foi aquecido a $37^{\circ} \mathrm{C}$ por 5 minutos em banho-maria, em todos os momentos, para avaliação da motilidade e integridade de membrana. Para a análise estatística foi utilizado o teste não paramétrico de Kruskal-Wallis, comparando-se os momentos de cada ejaculado.

\section{Resultados e discussão}

A Tabela 1 demonstra o percentual médio de motilidade espermática e taxa de integridade da membrana plasmática, comprovando a eficácia do diluidor "baken" usado no processo de resfriamento do sêmen canino, concordando com Moura (2000), ao afirmar que os diluentes à base de gema de ovo propiciam ambiente adequado para a criopreservação do sêmen de cão, e com os relatos de Province (1984), ao evidenciarem $50 \%$ de motilidade no sêmen de cão, durante o período de dois a quatro dias, utilizando diluidores contendo $20 \%$ de gema de ovo. Diferiram dos achados de Pinto et al. (1999), ao evidencieram motilidade em torno de $60 \%$, obtendo fertilidade de $100 \%$. O resultado da motilidade inferior ao encontrado nesse experimento pode estar relacionado com o fato de esses autores terem utilizado diluidor à base de leite desnatado (Kenney - Lane Manufacturing Inc., Denver, CO) demonstrando que a $5^{\circ} \mathrm{C}$, a ação crioprotetora do diluidor à base de leite desnatado sobre a célula espermática é inferior àquela exercida pela gema de ovo (Moura et al., 2002).

Tem sido reportada a presença de alguma glicose na gema de ovo (Salisbury et al., 1945). Espermatozóide de cães, os quais foram preservados em diluidores cuja glicose provinha apenas da gema de ovo, foram hábeis em manter $\geq 70 \%$ de motilidade durante os quatro primeiros dias de conservação e da preservação por mais de 21 dias de estocagem, demonstrando assim que a menor quantidade de glicose contida na gema de ovo em diluidores pode ser suficiente para preservar sêmen resfriado de cão por um período considerável. O diluidor utilizado neste experimento contém $3 \%$ de gema de ovo e $5 \mathrm{~g}$ de glicose para cada $100 \mathrm{ml}$ de diluente, o que pode ter contribuído para o aumento da motilidade, uma vez que suplementação com glicose ou frutose, resultou em aumento das taxas de motilidade em sêmen preservado de cão, quando adicionado ao diluidor contendo gema de ovo (Ponglowhapan et al., no prelo).

Tabela 1: Percentual médio de motilidade individual progressiva (MIP) e integridade da membrana plasmática (IMP) do sêmen de cão submetido ao processo de resfriamento com o diluidor baken modificado

\begin{tabular}{ccccccc}
\hline Parâmetro & M0 & M1 & M2 & M3 & M4 & M5 \\
\hline MIP (\%) & $90,00^{\mathrm{a}}$ & $87,50^{\mathrm{ac}}$ & $80,00^{\mathrm{ac}}$ & $77,50^{\mathrm{bc}}$ & $65,00^{\text {bd }}$ & $55,00^{\text {bd }}$ \\
IMP (\%) & $92,00^{\mathrm{a}}$ & $83,00^{\mathrm{ac}}$ & $80,00^{\mathrm{ac}}$ & $74,00^{\mathrm{bc}}$ & $69,00^{\text {bd }}$ & $63,00^{\text {bd }}$
\end{tabular}

Mo = após colheita; M1 = 24 horas; M2 = 48 horas; M3 = 72 horas; M4 = 96 horas; M5 = 120 horas.

Letras diferentes na mesma linha indicam diferença estatística $\left(P_{£} 0,05\right)$

A membrana plasmática apresentou redução de sua integridade, mantendo-se também preservada até 48 horas de resfriamento, de acordo com o Manual para Exame Andrológico e Avaliação Seminal - CBRA, discordando dos achados de Pinto et al. (1999), que obteve resultados em torno de $85 \%$, e de Cunha et al. (2003), com pouco acima de 
$75 \%$. A variação nesses resultados pode ser devida a fatores como: diferença nos procedimentos de preservação, como taxa de resfriamento, ou, até mesmo, diferenças nos métodos de estimar a porcentagem de motilidade (subjetivo ou objetivo) (Ponglowhapan et al., no prelo).

Apesar da combinação da gema de ovo com glucose poder otimizar a sobrevida espermática durante a estocagem (Bogard et al., 1950), pouco se sabe do efeito da associação de outros componentes existentes no extensor "baken", utilizado neste experimento, como a taurina, o cloreto de potássio e o fosfato ácido dissódico dodeca hidratado, sobre as células espermáticas no que diz respeito à fertilização, por isso, maiores estudos serão necessários para testar a fertilidade in vivo de sêmen de cão resfriado por muito tempo.

\section{Apoio: FAPESP}

\section{Referências}

ANDERSEN, K. Intrauterine inseminations with frozen semen in dogs. Nord. Vet. Congr. v. 12, p. 153-154, 1974.

BOGARD, R., MAYER, D. T. The effects of egg yolk on the various physical and chemical factors detrimental to spermatozoa viability. J. Anim. Sci., v. 9, p. 143-152, 1959.

BOUCHARD, G. F., MORRIS, J. K., SIKES, J. D., YOUNQUIST, R. S. Effect of storage temperature, cooling rates and two different semen extenders on canine spermatozoal motility. Theriogenology. v. 34, p. 147-157, 1990.

CUNHA, I. C. N.; LOPES, M. D. Estudo da viabilidade do sêmen canino utilizando-se diluidores à base de leite e glicina-gema. Rev. Bras. Reprod. Anim. v. 21, n. 2, p. 68-71, 1997.

CUNHA, I. C. N., ZÚCCARI, C. E. S. N.,COSTA e SILVA, E. V. Avaliação da viabilidade de um sistema passivo de refrigeração para a preservação e transporte de sêmen canino. Rev. Bras. Repr. Anim. v. 27, n. 3, 2003.

ENGLAND, G. C. W., PONZIO, P. Comparision of the quality of frozenthawed and cooled-rewarmed dog semen. Theriogenology. v. 46, p. 165-171, 1984.

FARSTAD, W. Bitch fertility after natural mating and after artificial insemination with fresh or frozen semen. J. Sm Anim. Pract. v. 25, p. 561-565, 1984.

FOOTE, R. H. The effects of electrolytes, sugars, glycerol and catalase on survival of dog sperm stored inbuffered-yolk mediums. Am J Vet Res., v. 25, p. 32-36, 1964.

GILL, H. P., KAUFMAN, C. F., FOOTE, R. H., KIRK, R. W. Artificial insemination of beagle bitches with freshly cooled, liquid stored, and frozen-stored semen. Am J Vet Res. v. 31, p. 1807-1813, 1970.

HARRISON, R. A. P.; VICKERS, S. E. Use of fluorescent probes to asses membrane integrity in mammalian spermatozoa. J. Reprod. Fertil., v. 88, p. 343-352, 1990.

LINDE-FORSBERG, C. Artificial insemination with fresh, chilled extended and frozen-thawed semen in the dog. Semin Vet Med Surg Small Anim., v. 10, p. 58, 1995.

MANUAL PARA EXAME ANDROLÓGICO E AVALIAÇÃO DO SÊMEN ANIMAL. CBRA - Colégio Brasileiro de Reprodução Animal, 2. ed., Belo Horizonte, 1998.

MELLO, S. L. V.; HENRY, M.; SOUZA, M. C.; OLIVEIRA, S. M. P. Effect of split ejaculation and seminal extenders on longevity of donkey semen preserved at 5 degree C. Arq. Brasi. Med. Vet. Zootec., v. 54, p. 372$378,2000$.
Um estudo com sêmen resfriado de cão, preservado em diluidor à base de gema de ovo e estocado a $4^{\circ} \mathrm{C}$ por quatro dias, demonstrou que a média de espermatozóides que se ligou à zona pelúcida in vivo, foi reduzida de 4,8 no dia um, para 0,9 no dia quatro (19). Embora esta diferença não seja significativa, os resultados indicaram que com o aumento na estocagem, a capacidade de ligação à zona pelúcida de sêmen de cão resfriado e estocado foi reduzida.

\section{Conclusão}

O meio "baken" modificado constitui diluidor eficaz no procedimento de refrigeração de sêmen de cão, podendo ser armazenado durante 48 horas em temperatura de $4^{\circ} \mathrm{C}$.
MORTON, D. B.; BRUCE, S.G. Semen evaluation, cryopreservation and factors relevant to the use of frozen semen in dogs. J Reprod Fertil., v. 39 (suppl), p. 311-316, 1989.

MOURA, C. S. Utilização de diferentes diluentes na criopreservação do sêmen de cão. 2000. 40 p. Monografia (Graduação em Medicina Veterinária) - UFRPE.

MOURA, C. S.; CAVALCANTI, M. C. O.; GUERRA, M. M. P.;BATISTA, A. M.; BARRETO, M. B. P. Teste de avaliação in vitro e criopreservação do sêmen de cão utilizando diferentes diluidores. Ver Brás Ci Vet., v. 9, n. 2, p. 102, 106, 2002.

NISHIKAWA, Y. Studies on reproduction in horses. Tokyo: Japan racing association, 1959.

PINTO, C. R. F.; PACCAMONTI, D. L.; EILTS, B. E. Fertility in bitches artificially inseminated with extended, chilled semen. Theriogenology., v. 52, p. 609-616, 1999.

PONGLOWHAPAN, S.; ESSÉM-GUSTAVSSON, B.; FORSBERG, C. L. Influence of glucose and fructose in the extender during long-term storage of chilled canine semen. Theriogenology, 2004.

PROVINCE, A. C.; AMANN, R. R.; PICKETT, B. W.; SQUIRES, E. L. Extenders for preservation on canine and equine spermatozoa at $5^{\circ} \mathrm{C}$. Theriogenology, v. 22, p. 409-415, 1984.

SALISBURY, G. W.; VANDEMARK, N. L. Stimulation of livability and glycolysis by addition of glucose to the egg-yolk-citrate diluent for ejaculated semen. Am J Physiol., v. 143, p. 692-697, 1945.

SCHAFER, S.; HOLZMAN, A.; ARBEITER, K. Investigation into the transmigration rate of short-term conservated canine sperm. Reprod Domest Anim., v. 32, p. 285-289, 1997.

SEAGER, S. W. J.; PLATZ, C. C.; FLETCHER, W. S. Conception rates and related data using frozen dog semen. J. Reprod. Fertil., v. 45, p.189-192, 1975.

SEAGER, S. W. J.; FLETCHER, W. S. Collection, storage, and insemination of canine semen. Lab Anim Sci., v. 1972, p. 177-182, 1972.

SILVA, A. R.; CARDOSO, R. C. S.; SILVA, L. D. M. Criopreservação do sêmen canino-Revisão. Ciência Animal. v. 11, n. 2, p. 119-129, 2001.

SILVA, K. M. G. Efeito dos antibióticos gentamicina e cefalotina e do aminoácido taurina em meio de gema de ovo (Baken) e leite desnatado (Kenney) sobre a longevidade e fertilidade do sêmen resfriado de eqüino. Botucatu, 2001. 108 p. Dissertação (Mestrado) - Faculdade de Medicina Veterinária e Zootecnia, Campus de Botucatu, Universidade Estadual Paulista.

STRÖM, H. B.; LARSSON, B.; LINDE-FORSBERG, C.; RODRIGUEZMARTINEZ, H. Evaluation of chilled and frozen-thawed canine spermatozoa using a zona pellucida binding assay. J Reprod Fertil. v. 119, p. 201-206, 2000. 